\title{
Bacterial flora of the appendix fossa in appendicitis and postoperative wound infection
}

\author{
D. A. LEIGH, KATE SIMMONS, AND EDELGARD NORMAN
}

From the Department of Microbiology, Wycombe and Amersham Hospitals, High Wycombe, Buckinghamshire

SYNOPSIS Bacteria were isolated from $153(47 \cdot 5 \%)$ swabs of the appendix fossa in 322 patients undergoing appendicectomy. The commonest organism was Bacteroides species found in $78 \%$ of specimens. Other Gram-negative bacilli such as Klebsiella, or Enterobacter, and Esch. coli were present in 29 and $27 \%$ respectively. Gram-positive cocci were less frequently isolated.

A positive culture was obtained more commonly in perforated appendicitis $(79 \%)$ than where chronic fibrosis, lymphoid hyperplasia, or acute appendicitis was present or when the appendix was normal. Bacteroides was isolated twice as often in perforated appendicitis.

The incidence of wound infection was $19 \%$ and varied according to the state of the appendix, being $63 \%$ in perforated appendicitis and $9.5 \%$ where lymphoid hyperplasia was present. Bacteroides was isolated from over $90 \%$ of the wound infections.

In the patients with perforated appendicitis where effective chemotherapy was given the incidence of wound infection was $15 \%$ whereas in untreated or inappropriately treated patients it was over $50 \%$.

The isolation of bacteroides requires special precautions to be taken both in the collection of the specimen and laboratory culture. It is important that the chemotherapy of postappendicectomy infections include an antibiotic active against bacteroides.

Appendicitis is a common condition which frequently requires emergency surgery. Postoperative wound infection has been reported in up to $30 \%$ of cases (Lancet, 1971) and this incidence can be influenced by many factors, the most important being surgical skill and technique and the criteria used to define the infection. Bacteria play an important role in appendicitis and the local application of antibiotics (Forbes, 1961; Rickett and Jackson, 1969) or antiseptics (Gilmore, Martin, and Fletcher, 1973) can reduce the incidence of wound infection. Despite the large number of studies into the infective complications of appendicitis, few workers have produced a detailed description of the associated bacteriology, and anaerobic bacteria which account for over $90 \%$ of the bacterial population of the intestine have rarely been reported. The relationship of preoperative bacterial flora of the peritoneal cavity surrounding the appendix to the degree of contamination is important in the development of wound infection. There is no agreement about the value of parenteral antibiotic treatment in acute appendicitis which

Received for publication 23 September 1974. might lead to the emergence of resistant bacteria (Garrod, 1972) but a clearer knowledge of the bacterial flora could result in the use of specific prophylactic therapy which might prevent postoperative sepsis.

This paper reports the results of bacteriological examination of swabs from the appendicular fossa in patients undergoing appendicectomy and the significance of these in the development of postoperative wound infection.

\section{The Patients and Methods}

All patients undergoing appendicectomy at the Amersham or Wycombe General Hospitals were included in the study. After opening the peritoneal cavity a swab was taken from the appendix fossa before the appendix was disturbed. The swab was immediately placed in Robertson's meat broth and delivered to the laboratory.

The swab was cultured directly onto blood agar, MacConkey agar, and a selective blood agar containing $0 \cdot 1 \%$ neomycin, haemin, and vitamin $\mathrm{K}$. The agar plates were incubated aerobically and 
anaerobically and were examined at 24 and 48 hours. The Robertson's meat broth was also incubated for 24 hours and then subcultured onto a similar set of agar plates. All bacteria isolated were identified by routine laboratory methods and antibiotic sensitivities were carried out by the disc technique. The subspecies of bacteroides was not determined in all strains but where it was identified the organism belonged to the subspecies fragilis.

Each patient was seen by the Control of Infection Sister and details of temperature, antibiotic therapy, and postoperative progress were obtained. All wound infections developing in patients in hospital were examined bacteriologically and culture was carried out as previously described.

Two to three weeks after discharge from hospital a questionnaire was sent to the patient's general practitioner requesting details of follow-up care, the development of wound infection, and any further bacteriological examination.

A wound infection was defined as the discharge of pus or purulent fluid from the operation wound with associated inflammation of the skin edges and pain.

\section{Results}

Between April 1973 and February 1974 appendicectomy was carried out on 322 patients: 122 were women, 102 men, and 98 were children under the age of 15 years.

Bacteria were isolated from $153(47.5 \%)$ of the swabs taken from around the appendix (table I). The commonest bacteria found were bacteroides species which were present in $119(78 \%)$ and the only other Gram-negative bacilli isolated frequently were Klebsiella and Enterobacter species and Esch. coli. Gram-positive cocci were found less commonly and were usually Strept. faecalis or anaerobic 용 streptococci. A pure growth of a single bacterial î strain was present in $65(42 \%)$ of the specimens and in $57 \%$ bacteroides species were isolated.

Bacteria were isolated more frequently in patients with perforated appendicitis (table II) and bacteroides species were present in $72 \%$ of the specimens. The rate of isolation of all bacteria and particularly bacteroides species was similar in the remaining four groups but there were distinct differences in the isolation of other Gram-negative bacilli. Klebsiella

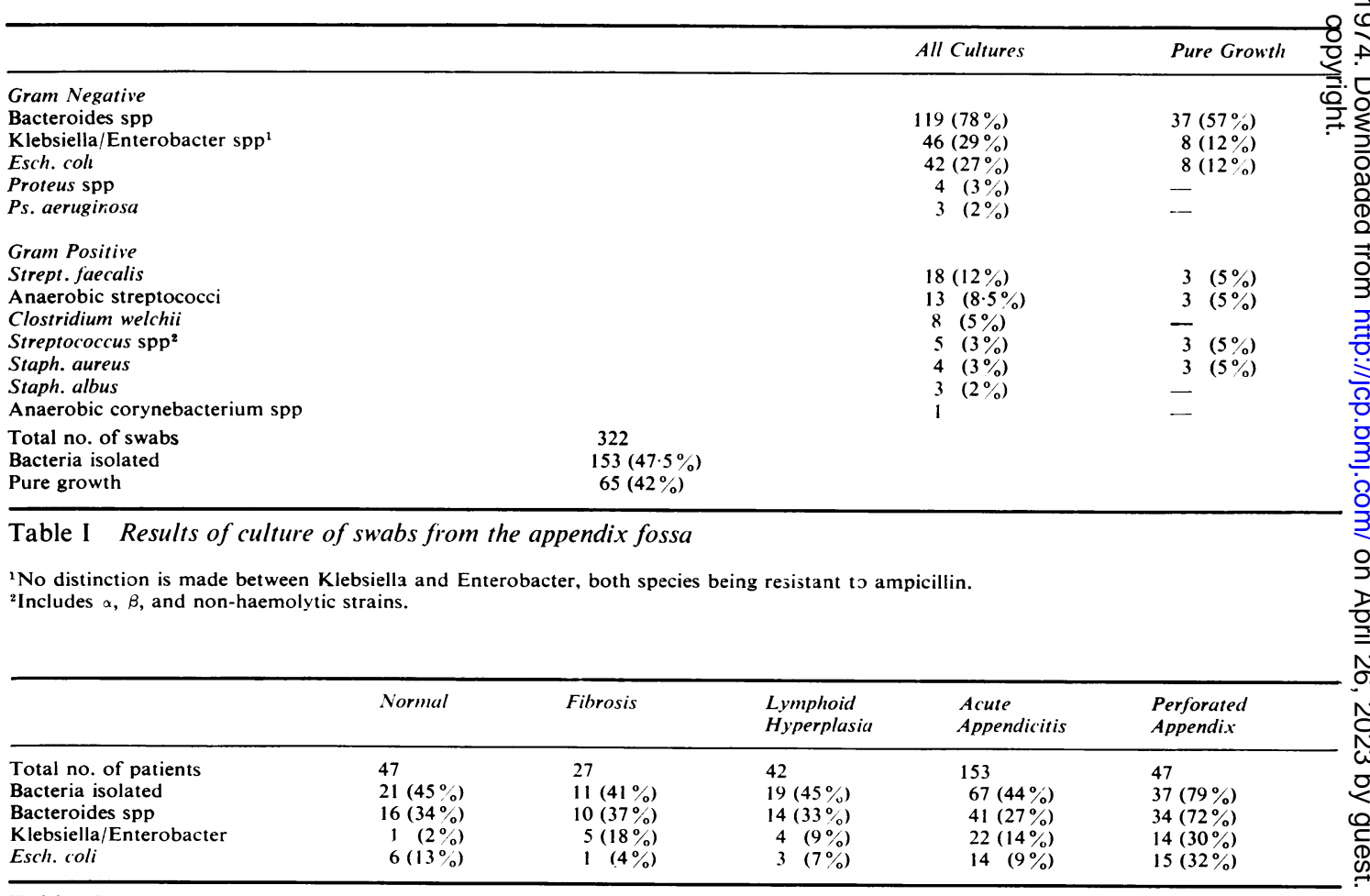

Table II Bacterial isolation compared with clinical and histological findings ${ }^{1}$

'No histological examination was carried out in six patients. 
and enterobacter species were more commonly isolated from chronic appendicitis whereas Esch. coli were predominant in patients with a normal appendix.

Fifty-nine $(19 \%)$ patients developed a wound infection after surgery and the incidence was higher in adults $(21 \%)$ than in children $(10 \%)$. Where the initial swab showed bacterial growth $27 \%$ of patients became infected and this incidence was $10 \%$ where no bacteria had been isolated. Nineteen patients with a perforated appendix received early effective antibiotic therapy and this may have prevented a wound infection.

The development of wound infection was related to the clinical appearance of the appendix and the histological findings (table III). The incidence was

\begin{tabular}{lrc}
\hline Clinical/Histological Findings & No. & Wound Infection \\
\hline Normal & 47 & $7(15 \%)$ \\
Fibrosis & 27 & $3(11 \%)$ \\
Lymphoid hyperplasia & 42 & $4(9 \cdot 5 \%)$ \\
Acute appendicitis & 153 & $26(17 \%)$ \\
Perforated appendix & 47 & $17(36 \%)$ \\
(excluding cases receiving appropriate & 27 & $17(63 \%)$ \\
$\quad$ treatment) & 6 & 2 \\
\hline Unknown & 6 & \\
\hline
\end{tabular}

Table III Wound infection and clinical and histological findings

highest $(36 \%)$ where the appendix had perforated and if the patients who received effective chemotherapy are excluded it rose to $63 \%$. The lowest incidence was seen with lymphoid hyperplasia.

Patients are discharged from hospital soon after appendicectomy and many of the wound infections develop at home. It was only possible to examine the wound bacteriologically in 32 of the 59 patients who developed an infection although all infected wounds were inspected clinically.

Bacteria were isolated from 30 infections and in 15 a single strain was found (table IV). Bacteroides species were cultured from $28(93 \%)$ of the swabs.

\begin{tabular}{lll}
\hline Bacteria & Pure Culture & Mixed Culture \\
\hline Bacteroides & $13(87 \%)$ & $15(100 \%)$ \\
Esch coli & 1 & 6 \\
Strept. faecalis & - & 4 \\
Klebsiella/Enterobacter & - & 3 \\
Streptococcus spp & - & 3 \\
Staph. aureus & - & 2 \\
Proteus spp & 15 & 2 \\
Total number & 15
\end{tabular}

Table IV Infecting organisms in wound infections

In two patients no bacterial growth was present probably due to concurrent antibiotic therapy.

There was a greater risk of developing a wound infection when bacteroides had been isolated on primary culture from the operation swab (table V). Bacteroides was also present in four of the five infections which followed an initial negative culture.

It was necessary to drain the peritoneal cavity in 51 patients and the incidence of wound infection was considerably higher $(49 \%)$ than where drainage was not needed $(9 \%)$.

Antibiotic treatment was given to 54 patients, including 28 with a perforated appendix. Where effective chemotherapy, usually parenteral lincomycin and ampicillin, was prescribed only three $(15 \%)$ of 22 patients developed a wound infection. The incidence of infection in untreated patients was $53 \%$ and in patients receiving ampicillin alone $67 \%$.

\section{Discussion}

The development of wound infection after appendicectomy is related to the severity of the appendicitis and is most common where perforation hasoccurred. It is important therefore to compare the incidence of infection with the histological and clinical findings. Although the overall incidence of wound infection in this group of 322 patients was $19 \%$, where perforation had occurred it was $63 \%$ (table III) confirming the reports of other workers (Crosfill, Hall, and London, 1969; Margarey, Chant, Rickford,

\begin{tabular}{|c|c|c|c|}
\hline & \multirow[t]{2}{*}{ Total } & \multicolumn{2}{|l|}{ Number Infected } \\
\hline & & Same Organism & No Swab Taken \\
\hline $\begin{array}{l}\text { Bacteroides (first culture) } \\
\quad \text { (second culture) } \\
\text { Esch. coli } \\
\text { Klebsiella/Enterobacter } \\
\text { Strept. faecalis }\end{array}$ & $\begin{array}{l}36 \\
39 \\
28 \\
46 \\
17\end{array}$ & $\begin{array}{r}12(33 \%) \\
4(10 \%) \\
4(14 \%) \\
3(6 \%) \\
1(6 \%)\end{array}$ & $\begin{array}{l}5 \\
2 \\
4 \\
3 \\
1\end{array}$ \\
\hline No growth & 151 & $\begin{array}{l}5(3 \%) \\
\text { Bacteroides } 4 \\
\text { Esch. coli } 1\end{array}$ & 12 \\
\hline
\end{tabular}

Table V Incidence of wound infection according to initial bacteriological findings in untreated patients only

'Subculture from Robertson's meat broth after 24 hours' incubation. 
and Magarey, 1971; Gilmore et al, 1973; Gilmore and Martin, 1974). The high incidence of wound infection $(15 \%)$ seen in patients with a normal appendix is probably related to contamination of the peritoneum and wound during the operation and emphasizes that care should be taken even when only minor resection of the intestine is necessary.

There are few reports of the bacteriology of appendicitis and the organisms have usually been referred to as 'the normal enteric flora'. Gilmore and Martin (1974) found Esch. coli to be the commonest organism isolated from the appendix fossa and bacteroides was only present in nine out of a group of 146 patients. In this study bacteroides species were isolated from the appendix swab nearly three times as frequently as any other bacterial strain (table I). It was the causative organism in 28 of the 30 wound infections examined bacteriologically and in $43 \%$ of patients it was found in pure culture.

The rate of bacterial isolation differed with the appendicular lesion, being nearly twice as high when perforation was present (table II). There was little difference in the incidence of bacteroides species in the various lesions except in patients with a perforated appendix where these organisms were found in $72 \%$ of the swabs. The isolation of other Gramnegative bacilli may reflect previous antibiotic therapy, particularly with ampicillin, as Klebsiella and Enterobacter species were mainly found in patients with chronic conditions of the appendix.

Drainage of the peritoneal cavity was associated with a greatly increased incidence of infection, but in contrast to other reports (Lancet, 1970; Magarey et al, 1971) the use of early parenteral antibiotic therapy did appear to prevent the development of wound infection especially in patients with a perforated appendix.

Bacteroides are anaerobic Gram-negative bacilli which are relatively difficult to isolate in the routine laboratory without special precautions (Leigh, 1974). Care must be taken in the collection of the swab and it must be delivered to the laboratory in special anaerobic transport media. It is necessary to use special selective culture media to allow easy identification, and blood agar containing neomycin $0.01 \%$ is commonly used. It has been shown that using these precautions the rate of isolation can be significantly increased (Hoffmann and Gierhake, 1969; Leigh, 1974).

Prophylactic therapy is only of value if it prevents infection, is simple to use, and is specific in its action. Many workers have shown that a reduction in the incidence of wound infection can be attained by the use of topical ampicillin powder (Rickett and Jackson, 1969), povidone iodine spray (Gilmore et $a l, 1973)$, or irrigation of the wound with tetracycline solution (Longland, Gray, Lees, and Garrett, 1971 ; Benson, Brown, and Whittaker, 1973). The use of parenteral chemotherapy with penicillin, streptomycin, ampicillin, or tetracycline has not been shown to be successful in preventing wound infection (Magarey et al, 1971; Longland et al, 1971), but three of these antibiotics have a very limited activity against bacteroides and the incidence of tetracycline resistance is relatively high. Although only a retrospective analysis was possible in this study, the use of lincomycin prescribed within 24 hours of appendicectomy reduced the incidence of wound infection in patients with a perforated appendix from over 50 to $15 \%$ and a prospective study is needed to show whether prophylactic lincomycin therapy given either as a single dose or a full course can prevent wound infection.

Most of the wound infections following appendicectomy, in common with all intestinal surgery, are caused by bacteroides and any prophylactic or therapeutic measures must include lincomycin or clindamycin which are at present the antibiotics with the greatest activity against these organisms.

We would like to thank Mr P. J. Phiels, Mr E. J Maquire, and Mr R. Pease, who were responsible fog collecting most of the swabs, and $\mathrm{Mr} \mathrm{P}$. H. Lord Mr B. Higgs, and Mr J. L. Grogono for allowing ue to study their patients.

Mrs K. Simmons is in receipt of a research grant from Beechams Research Laboratories.

\section{References}

Benson, E. A., Brown, G. J. A., and Whittaker, M. (1973). Prevention of wound infection in acute appendicitis. Lancet, 2, 322.

Crosfill, M., Hall, R., and London, D. (1969). The use of chlorhexidine antisepsis in contaminated surgical wounds. Brit. J. Surg. $56,906-908$.

Forbes, G. B. (1961). Staphylococcal infection of operation wounds with special reference to topical antibiotic prophylaxis. Lancet, 2, 505-509.

Garrod, L. P. (1972). Causes of failure in antibiotic treatment. Brit. med. J., 4, 473-476.

Gilmore, O. J. A., and Martin, T. D. M. (1974). Aetiology and prevention of wound infection in appendicectomy. Brit. $J$. Surg., 61, 281-287.

Gilmore, O. J. A., Martin, T. D. M., and Fletcher, B. N. (1973). Prevention of wound infection after appendicectomy. Lancet, 1, 220-222.

Hoffmann, K., and Gierhake, F. W. (1969). Postoperative infection of wounds by anaerobes. Germ. med. Mth., 14, 31-33.

Lancet (1970). Control of chemotherapy (Annotation). 1, 930-931.

Lancet (1971). Editorial. Sepsis after appendicectomy. 2, 195.

Leigh, D. A. (1974). The clinical significance of infections due to Bacteroides fragilis and the role of antibiotic therapy. Brit. med. J., 3, 225-228.

Longland, C. J., Gray, J. G., Lees, W., and Garrett, J. A. M. (1971). The prevention of infection in appendicectomy wounds. Brit. J. Surg., 58. 117-119.

Magarey, C. J., Chant, A. D. B., Rickford, C. R. K., and Magarey, J. R. (1971). Peritoneal drainage and systemic antibiotics after appendicectomy. Lancet, 2, 179-182.

Rickett, J. W. S., and Jackson, B. T. (1969). Topical ampicillin in the appendicectomy wound: report of a double-blind trial. Brit. med. J., 4, 206-207. 